\title{
Exploring Predictability in Armed Conflict
}

\author{
David E. McCullin
}

\begin{abstract}
This article proposes a direct relationship between complexity and predictability in a two-agent noncooperative zero-sum game (2XZSG). The author explores this proposition by modeling armed conflict as a XZSG and using case studies in armed conflict as the dataset for the systematic literature review. This article uses a multiple case study approach, systematically reviewing 13 case studies in armed conflict that yielded 156 references identifying four themes - environmental, human resource, operational, and supply chain constraints - that demonstrate a direct relationship between complexity and predictability. The data focuses on decisions made in particular battles and campaigns as well as the constraints that impacted decision making. By identifying those decisions and constraints, four themes emerged. These four themes are an innovation as a potential addendum to the war gaming methodology in the military decision making process (MDMP).
\end{abstract}

Keywords: game theory, complex adaptive systems, armed conflict, operational arts, war gaming, strategy selection

\section{Introduction}

\section{Concepts Defined}

he systematic literature review (SLR) is a well-established method of inquiry for social science research and is defined as an essential component of academic research. ${ }^{1}$ It summarizes, analyzes, and synthesizes a group

David E. McCullin is a doctoral candidate at the University of Maryland Global Campus. He holds a master's degree in national security and strategic studies from U.S. Naval War College in Newport, RI, and a master's degree in business policy and economics from State University of New York. McCullin has worked as an infrastructure analyst at the U.S. Department of Homeland Security, and prior to that retired from the U.S. Army with various tours, serving 12 years in Army Special Operations with the U.S. Army Civil Affairs and Psychological Operations Command. 
of related sources to identify gaps in the literature and create new knowledge. This study mirrors specific procedures and formatting of the SLR to ensure rigor and transparency to produce valid, reliable, and repeatable results.

This study defines deliberate planning in terms of simple constructs that describe planning as occurring when organizations take actions to influence future operations. According to David M. Reid, a wide body of consensus exists in the literature portraying planning processes by which organizations identify future opportunities. Other researchers agree that deliberate planning at the strategic level is widely applied. Reid states that identified complications causing a disconnect between strategic and operational planning typically occurs between the strategic and operational levels. These are the constructs employed in this article. $^{2}$

For the purposes of this discussion, a two-agent noncooperative zero-sum game (2XZSG) refers to a competitive situation where two independently acting agents seek to maximize their payoffs and minimize their losses relative to the other agent in the game. This means that any gain by one agent is forfeited by the other agent. This study employs the concept of a two-agent turn-based stochastic game (2TBSG) as explained by Thomas Dueholm Hansen and Ramsus Ibsen-Jensen, in which the characteristics of the game are turn-based rounds of actions; reactions; and counteractions, also called strategies. ${ }^{3}$

Each round of a 2XZSG produces a final state resulting from a finite set of actions. In any given round, each player attempts to minimize costs and maximize payoffs. These characteristics define armed conflict as a 2XZSG. In this context, combatants are players who initiate combat operations (i.e., rounds of the game where actions produce an end state) that result in victory (i.e., maximizing payoff with minimum cost) or defeat (i.e., maximizing cost with minimum payoff). In this context, armed conflict is framed as a stochastic game in recognition of the fact that the finite set of actions in each round are associated with probability. But determining the probability of an action in this context is an intuitive process based on supporting evidence rather than a pure mathematical solution.

In this study, complex adaptive systems are employed as defined by six seminal authors in complex systems theory. ${ }^{4}$ According to Benoit Morel, Rangaraj Ramanujam, Cesare M. Scartozzi, Andreas Ortmann, Leonidas Spiliopoulos, and Le Zhang, complex adaptive systems have three main characteristics: a large number of interacting elements such as people, places, and situations; feedback mechanisms that adapt the system by competition or gaming; and emergent properties that are empirically verifiable. ${ }^{5}$ Complex systems theory refers to a research perspective used to describe the different facets of complex systems based on the characteristics of the system studied, the analytical tools used, and the 
dominant paradigms that characterize the system. ${ }^{6}$ In this case, the system studied is armed conflict as a 2XZSG occurring in the complex adaptive system of international relations; the analytical tool is constraints analyses that identify predictable strategies; and the paradigm is armed conflict as an extension of politics to manage conflict. Because the complexities of this paradigm create constraints that limit strategy selection in armed conflict, a measure of predictability is added to armed conflict.

Bounded rationality refers to the idea that the limits of the human mind are challenged by the complex nature of obtaining, screening, and processing information and the process of interpreting that information for decision making. According to Herbert A. Simon, decision makers are capable of rational decision making until overwhelmed by the complexities within a system that limits human capabilities. At this point, rationality gives way to the decision maker's cognitive capability limitations, which is typically information the decision maker preconceives or rationalizes and is not based on evidence. ${ }^{7}$ This definition also relies on the concept of confirmation bias, in which decision makers favor information consistent with their beliefs while downplaying information that is inconsistent with their beliefs. ${ }^{8}$

The theory of constraints is defined as having origins in manufacturing but impacts many other applications that are involved in continuing improvement processes. Constraints are also framed in terms of duration and sequencing within a system. Eliyahu M. Goldratt explains that the theory of constraints is the basis for defining change as continuously improving performance. He also argues that constraints limit system performance. ${ }^{9}$ Mahesh Gupta and Joseph Kline identify and manage constraints with a five-step process: 1) find the system limits; 2) decide how to make full use of the system limits; 3) offer full support to those decisions; 4) break the system limits; and 5) continue to identify new constraints. ${ }^{10}$ These are the constructs employed in this article.

The approach for this study was to rely on the author's experience as a former planning practitioner and incorporate the author's new path as a scholar to conduct an inductive study on advanced strategic and operational planning to innovate the war gaming process in the MDMP and to provide the basis for further research in deliberate military planning.

The author's experience as an operational planner led to the proposition that complexity limits choice, and that limited choice in a game increases predictability. In strategic planning, the focus on constraints provides an alternative perspective, allowing commanders to inform decision from a new perspective. To explore that hypothesis, this article uses an SLR to examine the relationship between complexity and predictability in zero-sum games using a multiple case study approach. The model for this exploration is based on armed conflict 
Figure 1. Conceptual logic chain

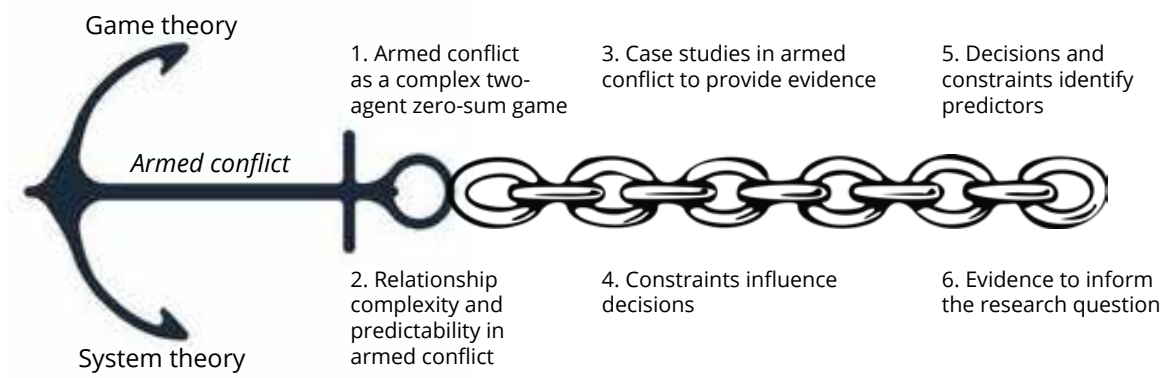

Source: Courtesy of the author, adapted by MCUP.

framed as both a complex adaptive system and a two-agent zero-sum game. This model will be explained in detail in the conceptual framework section and is depicted in figure 1.

\section{Problem Statement}

This study addresses a chasm between strategic and operational planning. The strategic and operational planning process often becomes static following the completion of a strategic plan for lack of a process to execute the goals and objectives of that plan, which creates a chasm between the two planning levels. In military planning, operational arts practitioners bridge the chasm between strategic and operational planning using a deliberate process that analyzes the actions; reactions; and counteractions, or wargaming strategy selection processes, of the agents in the game.

Organizations lacking a wargaming strategy selection processes fall into the chasm between strategic and operational planning and are forced to react to the obstacles impeding the completion of their goals and objectives rather than anticipate how to manage them (figure 2). Such a disconnect demonstrates the need for an implementable wargaming strategy selection processes. This study examines examples of armed conflict to offer planners an evidence-based approach to bridging these two types of planning. It also offers military operational arts practitioners an enhancement or alternative to deliberate planning processes specific to wargaming.

Excluding the introduction and background, this study contains four major sections. The first discusses the rigor and transparency associated with identifying the literature used in this appraisal. The second illustrates the quality of the literature using a weight of evidence framework. The third focuses on the coding and synthesis of the data from the identified sources. Finally, the fourth offers implications and recommendations. 
Figure 2. Planning chasm model

\section{INTRODUCTION/OBJECTIVE PROBLEM}

Examine a relationship between complex predictability to enhance decision making. Lack of a methodology to link strategic and operational planning identifies a planning chasm.

Strategic planning

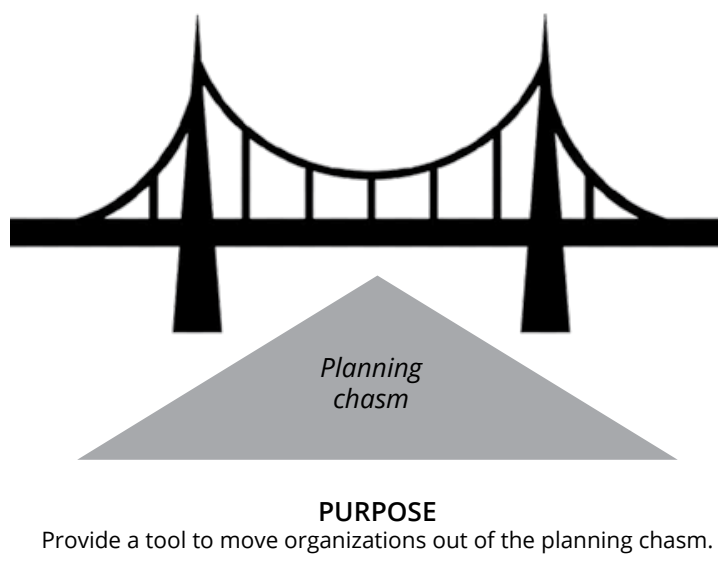

Source: Courtesy of the author, adapted by MCUP.

\section{Background}

\section{Theoretical Framework Constructs}

The theoretical lens for this study draws from the constructs of four established theories: game theory, complex systems theory, bounded rationality, and the theory of constraints (figure 3). Game theory frames armed conflict as a 2XZSG, the basics of which involve decision-making agents with opposing objectives, according to John von Neumann and Oskar Morgenstern. ${ }^{11}$ Another component of a 2XZSG is equilibrium, which, according to Mihai Alexandru Suciu, Gaskó Noémi, and Lung Rodica Ioana, occurs when game agents' payoffs are impacted by the decisions of the other game agents. ${ }^{12}$ A third component is cost. Hansen and Ibsen-Jensen explain that each agent's objective in a 2XZSG is to select strategies that maximize gains and minimize costs because each agent's gain is an opposing agent's loss. ${ }^{13}$

In this context, complexity theory frames armed conflict as a complex adaptive system with self-organization. Change is an integral part of complex adaptive systems because it keeps the system functioning through feedback loops, which act as adaptations to bring the system into a new steady state with new forms of organization. ${ }^{14}$ In armed conflict, it is often the case that an engagement takes an unanticipated turn that is subsequently addressed by innovation, which then becomes the new doctrine, as is the case in complex adaptive systems. The theory of constraints frames the concept of predictability in complex systems. 
Figure 3. Theoretical framework model

THEORETICAL FRAMEWORK

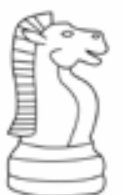

Game theory

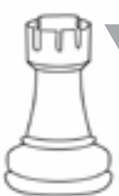

Bounded rationality

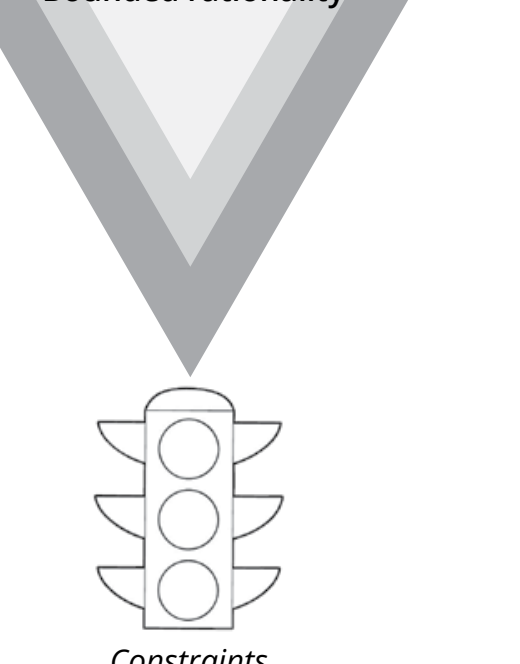

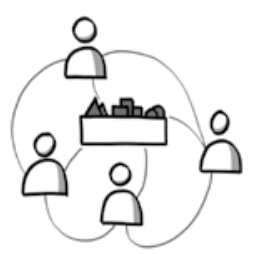

Complex systems

Source: Courtesy of the author, adapted by MCUP.

Shelja Jose Kuruvilla explains that the theory of constraints was originally a manufacturer's application, developed by Eliyahu M. Goldratt, that has evolved to employ concepts, principles, solutions, tools, and approaches designed for ongoing improvement using feedback loops similar to what occurs in complex adaptive systems. ${ }^{15}$ In this study, constraints are defined as instruments that identify predictable strategies in armed conflict. This study also discusses constraints as mechanisms that initiate innovation in armed conflict.

\section{Conceptual Framework}

Developing, staffing, mobilizing, adapting, and controlling the many interacting subsystems required to afford a nation or state the ability to engage in armed conflict makes armed conflict a complex adaptive system. As with any complex adaptive system, armed conflict incurs self-organizing subsystems that manifest as battlefield innovations. Additionally, the actions, reactions, and counteractions that occur in armed conflict classify it as a 2XZSG, where opposing agents attempt to enhance their payoffs at the expense of their opponents' payoffs through strategy selection (figure 4). The who, what, when, where, and how 
Figure 4. Conceptual framework

\section{CONCEPTUAL FRAMEWORK}

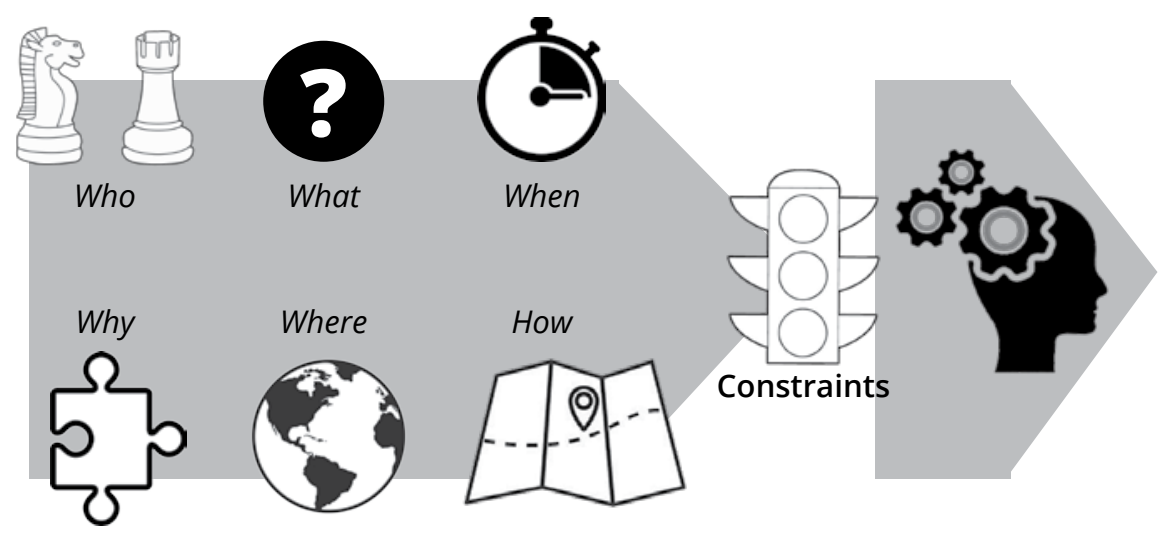

Source: Courtesy of the author, adapted by MCUP.

represent decisions; the traffic signal signifies constraints and innovation; and the human thinking icon represents predictability emerging from constraints.

This framing provided three advantages that facilitated data collection and analysis in this study. First, armed conflict is extensively covered in books, periodicals, and film documentaries, which provided a vast repository of case studies. Second, the use of case studies in armed conflict enabled the identification of decisions or gaming associated with executing campaigns and battles. Third, those case studies facilitated the analysis of constraints that influenced the decisions made. The SLR of sources on armed conflict, the identification and analysis of decisions and constraints, and the discovery of emerging themes provide evidence that defines the relationship between complexity and predictability in a 2XZSG.

\section{Research Question}

This research question is developed using the Population, Intervention, Comparison, Outcome, and Context (PICOC) guide from the Center for Evidence-Based Management's Guideline for Rapid Evidence Assessments in Management and Organizations: ${ }^{16}$

- Population: strategic planners engaging in zero-sum games, seeking payoffs that advance their agency relative to a competing agency.

- Intervention: an alternative methodology for considering strategy selection in zero-sum games.

- Comparison: the current process for strategy selection in de- 
liberate planning where the two-agent zero-sum games employed do not consider constraints that limit strategy selection. Comparatively, the existence of predictors in strategy selection afforded by complexity offer alternative considerations.

- Outcome: a tool for decision support in deliberate planning.

- Context: strategic planners and corporations planning counteractions resulting from an initial action and an agent's reaction.

Research Question: By viewing armed conflict as a complex adaptive system and a two-agent zero-sum game, what will a systematic review of case studies in armed conflict reveal about a relationship between complexity and predictability?

The criteria for inclusion is as follows:

- Studies relating to armed conflict.

- All case studies related to battle or campaign analysis.

- A systematic review of case studies.

- Open-ended dates of publication to present for meta-analyses and for primary studies.

- Analysis of the effects of decision making on organizational outcomes.

- Analysis of how decisions were impacted by constraints and what patterns, if any, were identified.

The criteria for exclusion is as follows:

- Studies in languages other than English

- Studies without a nexus to battle or campaign analysis.

- Studies or data not relevant to the PICOC.

The impetus for this study was preparing a manuscript as a precursor to the author's dissertation, which will also explore the relationship between complexity and predictability in 2XZSGs. The literary repository informing the dissertation has been under development for more than a year and is therefore the same repository used for this study. The dissertation repository includes more than 100 sources that were collected using specific search terms (table 1).

The overall data collection strategy was to implement a pull approach with a building block method. According to Eric Barends, Wendy Carroll, Blake Jelley, and Denise Rousseau, a pull approach refers to a five-part process that starts with a research question followed by a literature search, a critical appraisal of research, an approach to applying evidence, and the application of that 
Table 1. Search strategy

\begin{tabular}{lcc}
\hline Specific search terms & Sources & Connectors \\
\hline Case studies in world wars & 13,517 & \\
Case studies World War I; World War II & 600 & \\
Case studies in war & 41,887 & \\
Case studies in war AND & 1,639 & And: the battle of \\
\hline
\end{tabular}

Source: Courtesy of the author.

evidence. ${ }^{17}$ The building block method occurs as each search string informs and refines the following string, narrowing the range of sources until the final selections are made. The strategy used in this study was to bolster the author's existing dissertation repository with specific search strings and to narrow the field of literature with inclusion and exclusion criteria and random selection, ultimately choosing between 15 and 20 case studies. Supporting data for theoretical and conceptual frameworks were also needed, and additional search strings were designed to ensure that the data was available.

Machine learning facilitated the final selection of literature to review. The machine learning algorithms programmed into the search engine sorted the selection pool in terms of relevance in descending order, making the top of the list the best place to select relevant sources. The inclusion and exclusion criteria were then applied to the first 50 case studies in the search results list to select the final 20 sources (table 2).

\section{Data Extraction}

The data extracted from the case studies informed the research question and supported its theoretical and conceptual frameworks. Data was collected by reading the scholarly articles and extracting relevant references. Each case study covered a separate battle or campaign, which also represented a separate complex adaptive system and 2XZSG. Each case was reviewed to identify two factors: 1) a decision relating to executing a battle or campaign, and 2) the constraints that influenced that decision.

\section{Critical Appraisal and Data Synthesis}

This section explains the scoring of each case study by a weight of evidence framework, which was used to conduct the SLR for quality. ${ }^{18}$ The case studies were evaluated by criteria designated as weight of evidence "A," "B," "C," and "D." "A" is defined as generally appropriate research methods; "B" as methods appropriate to the specific research question; "C" as evidence appropriate to the research question; and “D” as an overall assessment. A numerical scale was ap- 
Table 2. Final data set of case studies

\begin{tabular}{|c|c|}
\hline Author & Title and year of publication \\
\hline Abbey, Josh & $\begin{array}{l}\text { "Two Blockades and a Battle: The Significance of } \\
\text { the Battle of Jutland" (2018) }\end{array}$ \\
\hline Alexander, Martin S. & $\begin{array}{l}\text { "After Dunkirk: The French Army's Performance } \\
\text { against 'Case Red,' } 25 \text { May to } 25 \text { June 1940" (2007) }\end{array}$ \\
\hline Anderson, Ross & “The Battle of Tanga, 2-5 November 1914" (2001) \\
\hline $\begin{array}{l}\text { Armstrong, Michael J., and } \\
\text { Steven E. Sodergren }\end{array}$ & $\begin{array}{l}\text { "Refighting Pickett's Charge: Mathematical Model- } \\
\text { ing of the Civil War Battlefield" (2015) }\end{array}$ \\
\hline Bechthold, Michael & $\begin{array}{l}\text { "'One of the Greatest Moments in My Life': Les- } \\
\text { sons Learned on the Canadian Battle of Norman- } \\
\text { dy Foundation Battlefield Tours" (2005) }\end{array}$ \\
\hline Bishop, Benjamin W. & $\begin{array}{l}\text { Jimmy Doolittle: The Commander behind the Legend } \\
\text { (2015) }\end{array}$ \\
\hline Gann, Timothy D. & $\begin{array}{l}\text { Fifth Air Force Light and Medium Bomber Operations } \\
\text { during } 1942 \text { and 1943: Building Doctrine and Forces } \\
\text { that Triumphed in the Battle of the Bismark Sea and } \\
\text { the Wewak Raid (1993) }\end{array}$ \\
\hline Grattan, Robert F. & $\begin{array}{l}\text { "Strategy in the Battle of Britain and Strategic } \\
\text { Management Theory" (2005) }\end{array}$ \\
\hline Haulman, Daniel L. & $\begin{array}{l}\text { "Before the D-Day Dawn: The Performance of the } \\
\text { Troop Carriers at Normandy" (2014) }\end{array}$ \\
\hline Hone, Trent & $\begin{array}{l}\text { "'Give Them Hell': The U.S. Navy's Night Combat } \\
\text { Doctrine and the Campaign for Guadalcanal" } \\
\text { (2006) }\end{array}$ \\
\hline Murray, Jennifer M. & "The Rebellion's Reality Check" (2019) \\
\hline Neiberg, Michael S. & $\begin{array}{l}\text { "The Evolution of Strategic Thinking in World War } \\
\text { I: A Case Study of the Second Battle of the Marne" } \\
\text { (2011) }\end{array}$ \\
\hline Philpott, William & "The Anglo-French Victory on the Somme" (2006) \\
\hline Salmi, Derek M. & $\begin{array}{l}\text { Slim Chance: The Pivotal Role of Air Mobility in the } \\
\text { Burma Campaign (2014) }\end{array}$ \\
\hline Sellick, Gary & $\begin{array}{l}\text { "They Were Marched Almost Day and Night': } \\
\text { The Effects of Sleep Deprivation on the Southern } \\
\text { Campaign of the American Revolution" (2016) }\end{array}$ \\
\hline Sica, Emanuele & $\begin{array}{l}\text { "June 1940: The Italian Army and the Battle of the } \\
\text { Alps" (2012) }\end{array}$ \\
\hline Stockings, Craig & $\begin{array}{l}\text { "The Anzac Legend and the Battle of Bardia" } \\
\text { (2010) }\end{array}$ \\
\hline Taylor, John & "Hitler and Moscow, 1941" (2016) \\
\hline $\begin{array}{l}\text { Vassie, John, and Byung Ho } \\
\text { Choi }\end{array}$ & $\begin{array}{l}\text { "Simulation of Normandy Invasion on 6th of June, } \\
\text { 1944" (2018) }\end{array}$ \\
\hline Winton, Harold R. & $\begin{array}{l}\text { "Airpower in the Battle of the Bulge: A Case for } \\
\text { Effects-Based Operations?" (2011) }\end{array}$ \\
\hline
\end{tabular}

Source: Courtesy of the author. 
Table 3. Critical appraisal (weight of evidence)

\begin{tabular}{l|l|l|l|l}
\hline Author & A & B & C & D \\
\hline Abbey, Josh & 2 & 2 & 2 & 2 \\
Alexander, Martin S. & 2 & 2 & 2 & 2 \\
Anderson, Ross & 2 & 2 & 2 & 2 \\
Armstrong, Michael J., & 2 & 2 & 2 & 2 \\
and Steven E. Sodergren & & & & \\
Bechthold, Michael & 3 & 2 & 3 & 3 \\
Bishop, Benjamin W. & 2 & 3 & 3 & 3 \\
Gann, Timothy D. & 1 & 2 & 3 & 2 \\
Grattan, Robert F. & 2 & 2 & 2 & 2 \\
Haulman, Daniel L. & 2 & 2 & 1 & 2 \\
Hone, Trent & 3 & 3 & 2 & 3 \\
Murray, Jennifer M. & 1 & 1 & 1 & 1 \\
Neiberg, Michael S. & 3 & 3 & 3 & 3 \\
Philpott, William & 2 & 2 & 2 & 2 \\
Salmi, Derek M. & 3 & 2 & 3 & 3 \\
Sellick, Gary & 3 & 3 & 2 & 3 \\
Sica, Emanuele & 3 & 2 & 2 & 3 \\
Stockings, Craig & 3 & 2 & 2 & 3 \\
Taylor, John & 2 & 2 & 2 & 2 \\
Vassie, John, and Byung Ho Choi & 1 & 1 & 2 & 2 \\
Winton, Harold R. & 3 & 2 & 3 & 3 \\
\hline Source: Courtesy of the author. & & & & \\
\hline
\end{tabular}

Source: Courtesy of the author.

plied to assess each weight of evidence category for all sources. The scale ranges from 1 to 3 , where 3 represents the highest quality and 1 represents the lowest (table 3).

\section{Synthesis}

The coding and synthesis employed in this SLR resulted in a total of 295 references being extracted from the 20 case studies, which were then translated into four themes representing identified constraints. Altogether, 149 references to environmental constraints came from 14 case studies; 42 references to human resource constraints came from 17 case studies; 58 references to operational constraints came from 17 case studies; and 46 references to supply chain constraints came from 17 case studies.

Environmental, human resource, and supply chain constraints uniquely interrelate with one another, identifying predictable strategies and influencing 
Figure 5. Operational constraint continuum

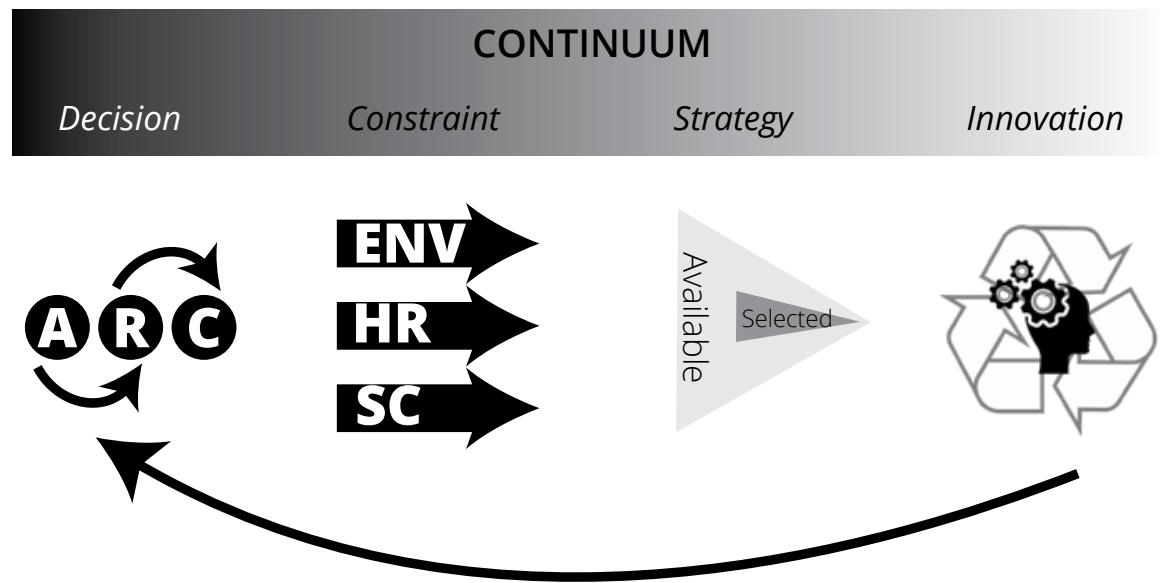

Note: $\mathrm{A}$ = actions; $\mathrm{R}=$ reactions; and $\mathrm{C}=$ counterreactions.

Source: Courtesy of the author, adapted by MCUP.

operational constraints. Operational constraints emerge from game decisions and circumvent environmental, human resource, and supply chain constraints with some operational innovation. This means that operational constraints emerge during a battle or campaign — an example being when new equipment faces outdated tactics, such as the employment of machine guns against a horse cavalry charge. This can be illustrated as a continuum (figure 5).

Operational constraints often result in some game-changing innovation that challenges current doctrine. Supply chain constraints emerge from logistical issues that range from concept through production to deployment. These issues are usually known, recognized, and incorporated into doctrine, and they also influence operational constraints that inspire innovation. Human resource constraints are those involved with fielding soldiers with the required skill sets that are task-organized for their assigned mission. This stretches from recruitment to deployment at the location where they engage in combat operations.

The first case study, describing Allied paratroopers in the invasion of Normandy during World War II, demonstrates how predictability emerges from constraints. Each theme is a compilation of constraints, which lends predictability to the war gaming strategy selection process. There is no particular order of importance or hierarchy among these themes, but as the examples that follow will prove, an interdependence among them is observed where the constraints of one theme impacts others. For example, the English Channel represents an environmental constraint in that crossing it merits considering factors such as distance, weather, and tides. It also involves supply chain constraints such as developing vehicles capable of navigating the distance, weather, and tides and 
human resource constraints of moving people with the necessary task-organized skill sets and capabilities to a location where they can be effective.

\section{Case Study Illustrations}

This section uses three case studies from World War II to provide a general example of how the 20 sources selected for this study were used to analyze decisions, identify constraints, and illustrate the emergence of predictability and innovation. The three case studies that will be subsequently described involve Allied paratroopers in the invasion of Normandy, the Siege of Bastogne during the Battle of the Bulge, and air mobility in the Burma campaign. These case studies illustrate the impact of environmental, human resource, operational, and supply chain constraints on limiting strategy selection in a 2XZSG.

\section{Allied Paratroopers in the Invasion of Normandy}

As told by Daniel L. Haulman in "Before the D-Day Dawn: The Performance of the Troop Carriers at Normandy," on 6 June 1944, 820 aircraft dropped more than 13,000 Allied paratroopers on the Cotentin Peninsula in northern France ahead of the main landing on the beaches of Normandy. ${ }^{19}$ The paratroopers' mission was to seize Sainte-Mère-Église, a hub of communication that included a causeway, which led to another D-Day objective-Omaha Beach. The drop, however, was not executed as planned. Approximately 80 percent of the paratroopers landed within 8 kilometers of their intended drop zones, which left them in makeshift command and control scenarios that endured for three days, after which time the Allied airborne divisions were able to reconstitute under their designated chains of command.

This description of airborne operations during the Normandy invasion illustrates how constraints influenced decisions and the predictability that emerged. The most obvious constraint was environmental-how to attack across the English Channel—which influenced both the Allied invaders and German defenders alike. The use of a large airborne force as a precursor to the main landing effort was an operational innovation designed to mitigate the environmental constraints associated with an attack across the channel. Aside from an amphibious crossing, an airborne assault was the only practical course of action to circumvent the environmental constraint, making it a predictable strategy.

Unsurprisingly, supply chain constraints guided the decision to capture critical transportation infrastructure that enabled battle sustainment. Specifically, as the troop airdrop was executed off target, the mission of seizing SainteMère-Église increased in importance to keep lines of communication open. The capture of Sainte-Mère-Église would enable the Allies to circumvent supply chain constraints and allow them to continue their offensive in German- 
occupied France from a logistical standpoint. Because of the supply chain constraints identified, the capture of communication infrastructure hubs became a predictable strategy.

An additional constraint occurring as a result of the airdrop was a human resource constraint. Because the majority of the paratroopers did not land in their intended drop zones, a human resource constraint was created, since they were not task-organized with the required skill sets or at the locations where they were required to complete the task at hand. This prompted a subsequent operational constraint in that the chains of command were disassociated. However, commanders on the ground innovated by reconstituting into makeshift units to complete the mission. Because of the human resource constraint resulting from the inaccuracy of the troop airdrop, the predictable strategy was to delay reconstitution of units by designation and create temporary units to continue the mission.

\section{The Siege of Bastogne during the Battle of the Bulge}

Harold R. Winton's "Airpower in the Battle of the Bulge: A Case Study for Effects-Based Operations?" demonstrates how constraints lead to predictability in strategy selection in 2XZSGs. ${ }^{20}$ As Allied forces moved from the beaches of Normandy across France and the Low Countries toward Berlin, they captured the town of Bastogne in Belgium. In the meantime, German forces planned a counterattack. Although the German offensive was anticipated by the Allied high command, there was no consensus as to where it would occur. Prior to the Battle of the Bulge, the Allies had advanced through France and Belgium on a wide north-south front with the forward edge of the battle area stretching from the Netherlands to Switzerland. On 16 December 1944, German forces launched their counterattack, pushing the Allies back and creating what appeared as a bulge on the Allies' situational map. The German offensive left the U.S. 101st Airborne Division surrounded at Bastogne for seven days, after which time it was relieved by elements of the U.S. Third Army.

Bastogne was significant as a hub for land and sea lines of communication, which are major enablers for circumventing environmental, human resource, and supply chain constraints that prevent the dispatching and free flow of personnel and equipment to sustain combat. Eight main roads leading through the difficult terrain of the Ardennes Forest passed through Bastogne, and the town also offered the best access to a major seaport at Antwerp, Belgium. Both the Allied and the German forces recognized the importance of Bastogne for these reasons. Because the Allies held Bastogne immediately prior to the Battle of the Bulge, environmental, supply chain, and human resource constraints were placed on the German forces, which denied them an environment where they could move freely. This, in turn, prevented them from dispatching human re- 
sources and establishing a supply chain to enable their warfighting capabilities.

Operationally, the Germans had lost Bastogne to the Allies in combat. Theoretically, they had forfeited Bastogne in a XXZS of armed conflict. Because of the environmental, human resource, and supply chain constraints placed on the German forces, their available strategy was limited to a counterattack at Bastogne. Although the actual time and location of the counterattack were not known by the Allies, Bastogne was the predictable location because it would enable the Germans to circumvent those identified constraints. According to the theory of constraints, constraints are associated with a longer duration before they are circumvented and a shorter duration after they are circumvented. Therefore, the longer the Germans waited to counterattack, the more constrained they would become in terms of time and space between the advancing Allied front and Bastogne. This made the counterattack imminent as opposed to delayed. The actions, counteractions, and reactions among the German and Allied forces thereby illustrates armed conflict as a 2XZSG occurring in a complex adaptive system where predictability emerges from complexity.

\section{Air Mobility in the Burma Campaign}

Derek M. Salmi's Slim Chance: The Pivotal Role of Air Mobility in the Burma Campaign demonstrates how a single battle became the catalyst for the emergence of a major shift in military doctrine. ${ }^{21}$ The Second Battle of Arakan marked the second Allied offensive in the Arakan Province of Burma against Imperial Japanese forces. This case study specifically illustrates an operational innovation that emerged from a 2XZSG in a complex adaptive system. In this example, the elements of the complex adaptive system are the environment, time, and the opposing Allied and the Japanese forces. In terms of environment, Burma is twice the size of Great Britain and nearly twice the size of Japan, spanning almost 420,000 square miles of jungle, hills, mountains, and swamps. The monsoon season lasts from May through October, and the country generally exists without main supply route networks. Finally, the Allied and Japanese forces were arrayed in an environment conducive only to jungle warfare.

After nearly two years of successes and defeats traded back and forth between the Allies and Japanese, the Second Battle of Arakan began in February 1944. In their movement to contact the enemy, the Allies were outflanked by the Japanese, who surrounded them and established roadblocks that diminished the Allied supply chain. The Japanese high command anticipated an attempted Allied withdrawal before they could close in and destroy the Allies. Rather than withdraw, however, the Allied forces dug in, forming a 1,000-square-yard defensive perimeter with interlocking fields of fire. Fairly consistent with their doctrine stipulating that forces should deploy with enough supplies to last 10 days - in actuality, they deployed with enough for just 7-the Japanese moved 
in for what they considered a rapid victory. Because their roadblocks diminished the Allied supply chain, the Japanese assumed the Allies would soon deplete their stores of ammunition and rations and be forced into capitulation. But while the roadblocks had weakened Allied resupply efforts, the Allies used modified aircraft to drop 60 tons of supplies into their defensive box perimeter daily. These innovations allowed the Allies to accomplish two critical factors attributable to their success: first, they were able to attrite the Japanese forces, who ultimately ran out of rations and ammunition; and second, they were able to fix their location around the box perimeter, allowing time for the arrival of reinforcements. These innovations resulted in new doctrine on air supply.

This study has proposed a direct relationship between complexity and predictability in a XXSG and explored this proposition by framing armed conflict as a complex adaptive system and a XXZSG. The data was extracted from case studies in war where command decisions are recognizable. As demonstrated in the three case studies above and the SLR synthesis, identifying constraints can reveal predictable strategies. This both informs the research question and indicates a direct relationship between complexity and predictability in a 2XZSG.

\section{Limitations}

This study has provided evidence of a positive relationship between complexity and predictability in a XZSG with four themes. Based on these results, organizations without a war gaming strategy selection process can select strategies based on an analysis of environmental, human resource, operational, and supply chain constraints to create the basics of a war gaming strategy selection process. Although this basic 2XZSG approach will move an organization away from the planning chasm, this study does not account for three important factors. First, the numerous applications of 2XZSGs that occur throughout society in our daily dealings with one another and are not executed by planning practitioners were not considered. Second, the predictive themes identified in this article overlap with one another, seemingly influencing decisions with a level of interdependency that was not measured or explored. Third, adverse selection theory is an additional lens through which to view supplementary research on this topic.

\section{Implications for Further Research and Recommendations for Practice}

This study uses the constructs of 2XZSGs, complex adaptive systems, and armed conflicts as a conceptual model to explore how complexity limits strategy selection and adds predictability to gaming. To demonstrate implications and make recommendations, the following example of a combat scenario will be explained and subsequently deconstructed for general management application. 
Corporate strategists should treat planning as a 2 XZSG and a complex adaptive system by evaluating their planned actions, reactions, and counteraction in terms of environmental, human resource, operational, and supply chain constraints to identify predictable strategies that support their decisions. In the Bastogne case study, the mission of the Allied forces was to maintain a warfighting capability by holding the town. To do this, they needed to mobilize people and equipment over time and space. The planning for this change could be accomplished by analyzing the constraints relating to planned actions, competitor's reactions, and subsequent counteractions to look for predictable strategies and make decisions.

Four recommendations resulted from this study, three of which center on the previously identified limitations. The first is to reframe the problem statement to apply to numerous applications of game theory occurring in society rather than solely to the chasm between strategic and operational planning. The second is to further develop the four themes to explore whether or not the resulting codes will function independently or overlap as identified in this article. The third is to add adverse selection theory to the existing theoretical framework constructs to explore how asymmetric information impacts strategy selection by using constraints analysis. Finally, the fourth is to develop a conceptual model for war gaming strategy selection process with an applied constraints analysis. A conceptual model will allow the development of a Constraints Analyzing War Gaming Strategy Selection Process (CAWGSSP) to be tested against the basic Nash equilibrium prisoner's dilemma game in which agents attempt to enhance their payoffs relative to opponents' payoffs through strategy selection. ${ }^{22}$ These recommendations will contribute to the growing body of knowledge associated with game theory.

\section{Endnotes}

1. Guy Paré et al., "Synthesizing Information Systems Knowledge: A Typology of Literature Reviews," Information \& Management 52, no. 2 (March 2015): 183-99, https:// doi.org/10.1016/j.im.2014.08.008.

2. David M. Reid, “Operational Strategic Planning," Strategic Management Journal 10, no. 6 (November-December 1989): 553-67; John Darragh and Andrew Campbell, "Why Corporate Initiatives Get Stuck?," Long Range Planning 34, no. 1 (February 2001): 33-52, https://doi.org/10.1016/S0024-6301(00)00095-9; Wolf-Christian Gerstner et al., "CEO Narcissism, Audience Engagement, and Organizational Adoption of Technological Discontinuities," Administrative Science Quarterly 58, no. 2 (2013), 257-91, https://doi.org/10.1177/0001839213488773; and Ronald Klingebiel and Arnoud de Meyer, "Becoming Aware of the Unknown: Decision Making during the Implementation of a Strategic Initiative," Organization Science 24, no. 1 (2012): 133-53, https:// doi.org/10.1287/orsc.1110.0726.

3. Thomas Dueholm Hansen and Ramsus Ibsen-Jensen, "The Complexity of Interior Point Methods for Solving Discounted Turn-Based Stochastic Games," in The Nature of Computation: Logic, Algorithms, Applications, ed. Paola Bonizzoni, Vasco Brat- 
tka, and Benedict Löwe (Berlin, Germany: Springer, 2013), 252-62, https://doi.org /10.1007/978-3-642-39053-1_29.

4. Benoit Morel and Rangaraj Ramanujam, "Through the Looking Glass of Complexity: The Dynamics of Organizations as Adaptive and Evolving Systems," Organization Science 10, no. 3 (May-June 1999): 279-80, https://doi.org/10.1287/orsc.10.3.278; and Cesare M. Scartozzi, "A New Taxonomy for Relations: Rethinking the International System as a Complex Adaptive System," Journal on Policy and Complex Systems 4, no. 1 (Spring 2018): 109-33.

5. Andreas Ortmann, Leonidas Spiliopoulos, and Le Zhang "Complexity, Attention and Choice in Games Under Time Constraints: A Process Analysis," Journal of Experimental Psychology: Learning, Memory, and Cognition 44, no. 10 (2018): 1609-40, https:// dx.doi.org/10.2139/ssrn.2620163.

6. Morel and Ramanujam, "Through the Looking Glass of Complexity."

7. Herbert A. Simon, "A Behavioral Model of Rational Choice," Quarterly Journal of Economics 69, no. 1 (February 1955): 99-118, https://doi.org/10.2307/1884852.

8. Amos Tversky and Daniel Kahneman, "Judgment under Uncertainty: Heuristics and Biases,” Science 185, no. 4157 (September 1974): 1124-31, https://doi.org/ 10.1126 /science.185.4157.1124; Susan T. Fiske and Shelley E. Taylor, Social Cognition, 2d ed. (New York: McGraw-Hill, 1991); and Hayagreeva Rao, Henrich R. Greve, and Gerald F. Davis, "Fool's Gold: Social Proof in the Institution and Abandonment of Coverage by Wall Street Analysts," Administrative Science Quarterly 46, no. 3 (September 2001): 502-26, https://doi.org/10.2307/3094873.

9. Eliyahu M. Goldratt, What Is This Thing Called the Theory of Constraints and How Should It Be Implemented? (Croton-on-Hudson, NY: North River Press, 1990); and Eliyahu M. Goldratt and Jeff Cox, The Goal: A Process of Ongoing Improvement (Crotonon-Hudson, NY: North River Press, 1984).

10. Mahesh Gupta and Joseph Kline, "Managing a Community Mental Health Agency: A Theory of Constraints Based Framework," Total Quality Management \& Business Excellence 19, no. 3 (March 2008): 281-94, https://doi.org/10.1080/14783360701601850.

11. John von Neumann and Oskar Morgenstern, Theory of Games and Economic Behavior (Princeton, NJ: Princeton University Press, 1944).

12. Mihai Alexandru Suciu, Gaskó Noémi, and Lung Rodica Ioana, "Approximation of Nash Equilibria and the Network Community Structure Detection Problem," PLoS One 12, no. 5 (2015): e0174963, https://doi.org/10.1371/journal.pone.0174963.

13. Hansen and Ibsen-Jensen, "The Complexity of Interior Point Methods for Solving Discounted Turn-Based Stochastic Games."

14. Elizabeth Eppel, "Complexity Thinking in Public Administration's Theories-in-Use," Public Management Review 19, no. 6 (June 2017), 845-61, https://doi.org/10.1080 /14719037.2016.1235721.

15. Shelja Jose Kuruvilla, "Theory of Constraints and the Thinking Process," International Journal of Business Insights \& Transformation 11, no. 1 (2017): 10-14.

16. This study is a systematic review, which is a tool of evidence based management. The Center for Evidence-Based Management is a professional organization advancing the use of systematic review. Their PICO framework is the most common research question framework used in SLRs. Eric Barends, Denise M. Rousseau, and Rob B. Briner, eds., CEBMa Guideline for Rapid Evidence Assessments in Management and Organizations (Amsterdam: Center for Evidence-Based Management, 2017).

17. Eric Barends et al., "Evidence-Based Management: Three New Approaches to Teaching the Practice of Management" (presentation, Professional Development Workshops, Annual Academy of Management, Boston, MA, 4 August 2012).

18. David Gough, "Weight of Evidence: A Framework for the Appraisal of the Quality and Relevance of Evidence," Research Papers in Education 22, no. 2 (2007): 213-28, https://doi.org/10.1080/02671520701296189.

19. Daniel L. Haulman, "Before the D-Day Dawn: The Performance of the Troop Carriers at Normandy," Air Power History 61, no. 2 (Summer 2014): 7-13. 
20. Harold R. Winton, "Airpower in the Battle of the Bulge: A Case Study for Effects-Based Operations?," Journal of Military \& Strategic Studies 14, no. 1(Fall 2011): 1-22.

21. Derek M. Salmi, Slim Chance: The Pivotal Role of Air Mobility in the Burma Campaign (Maxwell Air Force Base, Alabama: Air University Press, Air Force Research Institute, 2014).

22. The CAWGSSP is conceptualized as a turn-based game played out in rounds of actions/reactions and counteractions. The prisoner's dilemma game is played out in a similar way. The prisoner's dilemma game is a well-established model that is the basis for illustrating the play of a zero-sum game. The author advocates further study to develop a model to be compared to the Nash model in addition to the planning innovation for the MDMP. Nash equilibrium refers to an economic theory developed by Nobel laureate John F. Nash Jr. 